\title{
Correction to: Downregulation of nicotinamide N-methyltransferase inhibits migration and epithelial-mesenchymal transition of esophageal squamous cell carcinoma via Wnt/ $\beta$-catenin pathway
}

\author{
Yanyan Cui ${ }^{1} \cdot$ Luyu Zhang ${ }^{1} \cdot$ Wenjie Wang ${ }^{1} \cdot$ Shanshan $\mathrm{Ma}^{1} \cdot$ Hongtao $\mathrm{Liu}^{1} \cdot$ Xingxing Zang $^{3} \cdot$ Yanting Zhang $^{1}$. \\ Fangxia Guan ${ }^{1,2}$
}

Published online: 18 July 2020

(c) Springer Science+Business Media, LLC, part of Springer Nature 2020

\section{Correction to: \\ Molecular and Cellular Biochemistry (2019) 460(1-2):93- \\ 103 \\ https://doi.org/10.1007/s11010-019-03573-0}

Figure $6 \mathrm{c}$ has been published incorrectly in the original article. The correct version of Fig. 6 is provided in this erratum.

The original article can be found online at https://doi.org/10.1007/ s11010-019-03573-0.

Yanting Zhang

zhangyt@zzu.edu.cn

$\triangle$ Fangxia Guan

fxguan@126.com

1 College of Life Sciences, Zhengzhou University,

Zhengzhou 450001, China

2 Henan Provincial People's Hospital, Zhengzhou 450003,

China

3 Department of Microbiology and Immunology, Einstein

College of Medicine, 1300 Morris Park Ave, Bronx,

NY 10461, USA 
Fig. 6 Knockdown of NNMT suppresses migration, EMT, and $\mathrm{Wnt} / \beta$-catenin pathway in ESCC cells. a Number of migrated cells was evaluated by a Transwell assay following NNMT knockdown in EC9706 and TE1 cells. b Quantitative results of the number of migrated cells. c Cell migration distance was observed using a wound healing assay at 0 and $48 \mathrm{~h}$ after NNMT downregulated in EC9706 and TE1 cells. d Quantitative results of the cell migration distance. e Protein expression levels of $\beta$-actin, E-cadherin, N-cadherin, Vimentin, $\beta$-catenin, GSK3 $\beta$, and p-GSK3 $\beta$ (Ser9) were analyzed by Western Blotting following NNMT knockdown in EC9706 and TE1 cells. $\beta$-actin was used as an internal control. Data are shown as mean $\pm \mathrm{SD}(n=3)$. ${ }^{*} p<0.05$ versus the untreated and NC groups
A

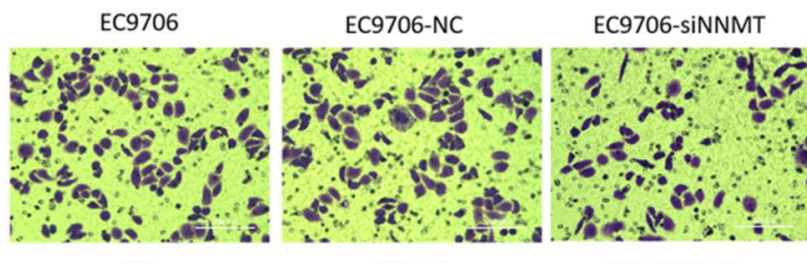

TE1

TE1-NC

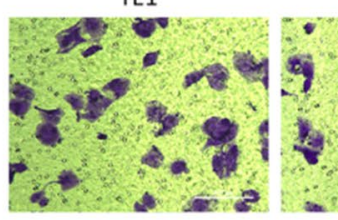

C

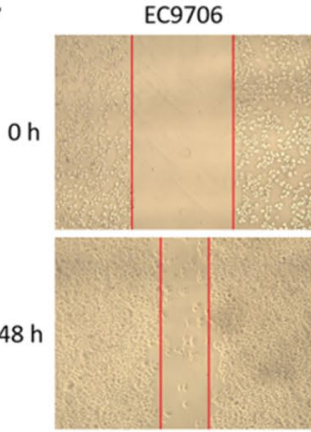

TE1
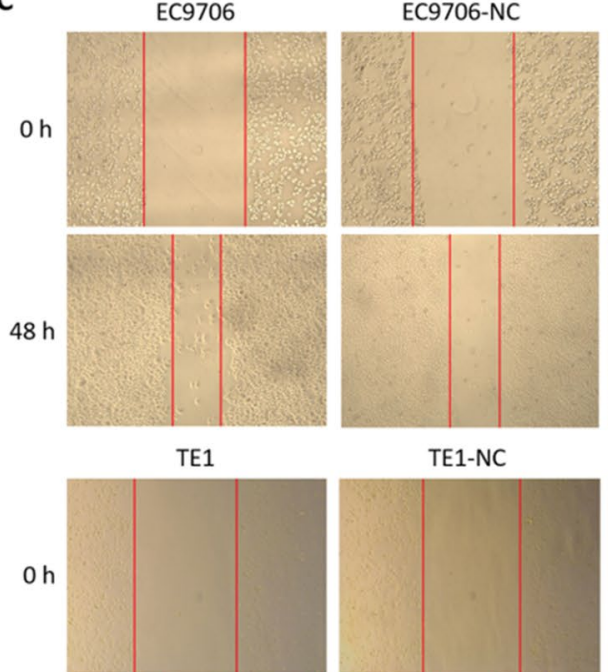

TE1-NC
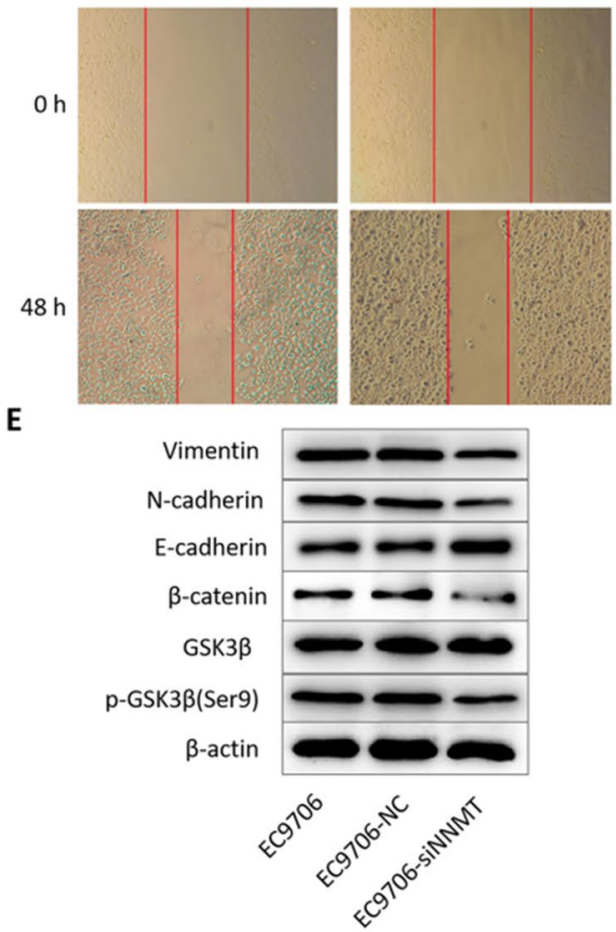

E
B

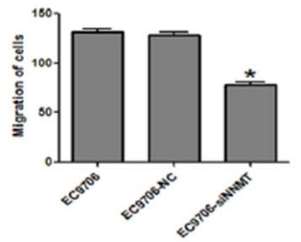

TE1-siNNMT

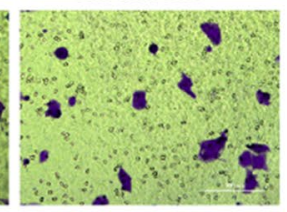

EC9706-siNNMT

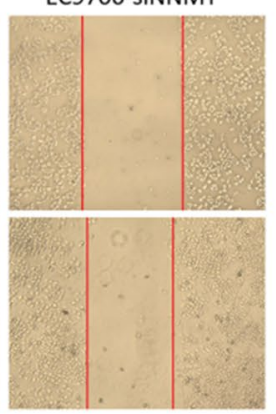

TE1-siNNMT
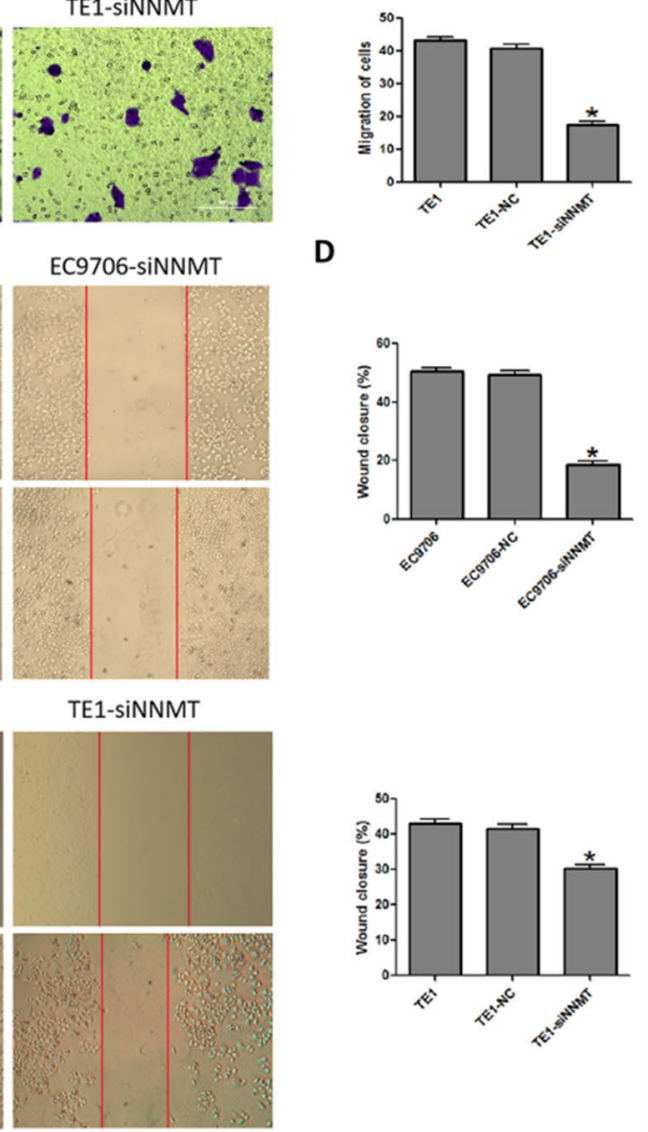

D
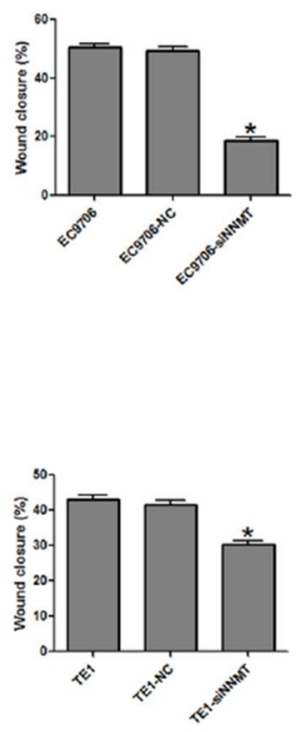

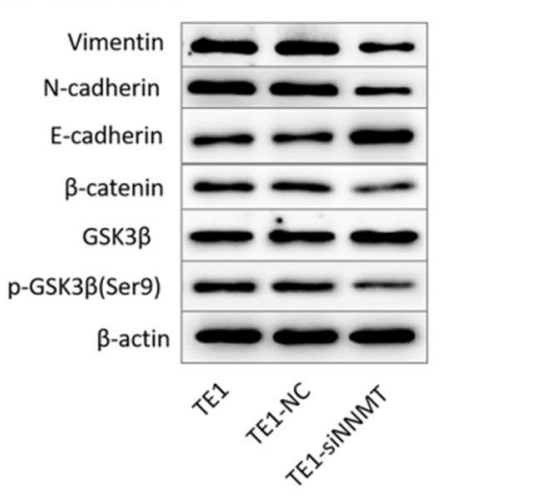

Publisher's Note Springer Nature remains neutral with regard to jurisdictional claims in published maps and institutional affiliations. 